\title{
O ALUNO DE GRADUAÇĀo E A PESQUISA CIENTÍfICA
}

\author{
Maria Itayra Coelho de Souza Padilha ** \\ Maria Teresa Coimbra de Carvalho ****
}

PADILHA, M. I. C. de S.; CARVALHO, M. T. C. de. O aluno de graduaçáo e a peoquisa cientifica. Rev. Esc. Enf. USP, v. 27, n.2, p. 281-95, ago. 1993.

Investigaçào a respeito da percepşio e conhecımento dos alunos de Graduaçáo em Enfermagem sobre a pesquisa científica e o seu uso. A Metodologia é qualitativaanálise de conteúdo. O universo e uma escola de enfermagem pública do Rio de Janeiro, a amostra sào 36 alunos e o instrumento é um Roteiro com 6 questỏes. Os alunos tem conhecimento relativo a pesquisa cientifica adquirido no decorrer da graduaça, mas principalmente a partir do $6^{\circ}$ periodo. Acham o método cientifico importante para seu desenvolvimento. Escolhem a disciplina Introduçào a Pesquisa para aprender, para elaborar monografias, crescimento profissional e para cumprir créditos.

UNITERMOS: Pesquisa, Enfermagem. Alunos de Graduaçāo

\section{CONSIDERAÇŌES INICIAIS}

No contexto brasileiro, a partir da Reforma Universitária e. da Lei de Diretrizes e Bases da Educação Nacional que aponta a pesquisa como uma das finalidades da universidade e as exigèncias contidas no Parecer 163/72 (BRASIL, 1974), referente ao curriculum minimo para os Cursos de graduaçăo em enfermagem, evidencia-se a criaçāo dos cursos de pós-graduaçāo, bem como, a necessidade de incluir os conteúdos de pesquisa no currículo de graduação.

Desde então, o aprimoramento dos métodos científicos vem suscitando uma busca incessante principalmente no que se refere a área docente, na medida em que o contato com a produção científica é atualizada.

$\mathrm{Na}$ área assistencial, nota-se que este interesse nảo se dá com tanta freqüência, tendo em vista, que os enfermeiros desconhecem o que vem sendo desenvolvido em termos de pesquisa, não participam.

\footnotetext{
- Professora Assistente do Departamenlo de Metorologa da Enfermagem da EEANiUfRA. Mestre rm Finfermagem e Livre. Docente em Exercicio da Eufermingem.

-. Professora Adjunta do Departamento de Metodologia da Enfermagem da EEAN/LFRJ. Mestre rm Enfermagem
} 
utilizam com menos freqüência em seus cenários de prática, têm dificuldades do acesso a bibliografias, pouco tempo disponível para estudos, falta de incentivo para pesquisar e para educaçāo continuada, etc. (LOPES, 1983 e CASTRO et al. 1985). Ainda nota-se um enorme distanciamento entre as concepçöes teóricas da comunidade científica e intelectual de enfermeiros sobre a importância e valorização dos resultados das pesquisas para serem aplicados nos cenários de prática (CASTRO et al, 1985).

A Enfermagem no Brasil é uma profissäo nova, em busca de arcabouços teóricos para fundamentar a sua prática, já que até o momento, transplantam as teorias e os métodos científicos dos países do $1^{\circ}$ mundo, que nem sempre se adequam as necessidades e realidades brasileiras (PORTO, 1990).

Portanto, acreditamos na importância de incentivar o ensino de pesquisa desde a graduaçāo, a fim de formar um profissional com maior senso crítico, criativo e sensibilizado pelo uso do método científico incorporando-o na prática em seu dia a dia, contribuindo assim, para formar e desenvolver o corpo de conhecimento da enfermagem. Conseqüentemente, observa-se que as dificuldades percebidas quanto a produçāo e a incorporação dos resultados de pesquisas na prática de enfermagem seräo minimizados.

Sabe-se que, os estudos sobre o ensino de pesquisa tèm sido desenvolvidos, tornando evidente que os educadores que desempenham suas atividades na graduaçäo tèm percebido a relevància da pesquisa para o desenvolvimento científico de seus paises, para o crescimento do campo de conhecimento respectivo, e conseqüentemente para a formaçáo de novas geraçōes de pesquisadores. (RODRIGUEZ, 1979).

A atividade científica dos estudantes contribui para a sua formaçăo integral. Os benefícios dela se traduzem por: formação de uma concepção científica do mundo; estabelecimento de uma inclinação permanente para a auto-aprendizagem e para o trabalho em equipe e individual; uso do trabalho científico traduzido em soluçōes inovadoras para os problemas, aumento do conhecimento através da busca de informaçōes e da organização e utilização crítica da mesma; escolha correta da formaçáo específica dentro da área de conhecimento onde se desenvolve; aprofundamento e ampliaçào da visão dos problemas fundamentais do país e da demanda dos esforços da sociedade em desenvolvimento; estabelecimento de atitudes positivas de modéstia, tenacidade e disciplina; aproximação de docentes e estudantes num trabalho em comum e a contribuiçāo para desenvolver e ampliar linhas de pesquisa em suas instituições de ensino. (AMADOR, $1984 \mathrm{e}$ RODRIGUEZ, 1979).

Alguns trabalhos explicitam papéis para o professor de pesquisa na graduação, sem maiores aprofundamentos, tais como: orientador 
e aconselhador que alivia a ansiedade do estudante, encorajando-o para aprofundar as abordagens de ensino, e estimulador das potencialidades do estudante para a pesquisa. Outro estudo se reporta as atividades que o professor desenvolve num curso de processo de pesquisa. Estas atividades aparecem vinculadas as etapas do processo de pesquisar, e se resumem em selecionar, identificar, exemplificar, orientar e citar. (RINEHART, 1976).

Nota-se que as dificuldades dos enfermeiros em produzir e consumir pesquisas ligadas a sua formaçāo na graduaçāo, encontram-se colocadas um contexto global de desenvolvimento da pesquisa em enfermagem.

Estas razōes nos levaram a investigar com mais profundidade a percepção e o conhecimento dos alunos de graduaçāo em enfermagem sobre o processo de investigaçāo científica, visando criar estratégias de ensino adequadas as necessidades do aluno despertando assim, o interesse deste para a utilizaçāo do método científico.

\section{OBJETIVOS}

- Identificar o conhecimento do aluno de graduação em enfermagem sobre a pesquisa científica;

- Verificar a percepção do aluno de graduação sobre os benefícios e o uso do método científico.

\section{METODOLOGIA}

\section{- Tipo de Estudo}

Este estudo é descritivo qualitativo usando o método de análise conteúdo, levando em conta a natureza do problema que nos propomos a investigar, o qual, segundo KIENTZ (1973), deve ser abordado como análise das comunicaçōes dos atores sociais envolvidos.

\section{- Universo}

São os alunos de graduaçāo em Enfermagem e Obstetrícia de uma Escola pública de Enfermagem do Rio de Janeiro, que freqüentou a disciplina eletiva Introdução a Pesquisa em Enfermagem.

\section{- Grupo Amostral}

Foram selecionados 36 alunos da disciplina eletiva Introduçāo a pesquisa em enfermagem, obedecendo aos seguintes critérios:

- já terem tido algum conteúdo teórico sobre pesquisa científica, e 
- estarem cursando o último ano do curso de graduação de Enfermagem e Obstetrícia.

\section{- A Construção do Instrumento}

Foi elaborado um Roteiro denominado pré-teste, contendo 05 questōes abertas relativas ao tema proposto; sendo estas referentes $\mathrm{a}$ :

- O que é pesquisa científica para você?

- Quando você ouviu falar pela primeira vez em pesquisa científica?

- Quais os passos primordiais para o desenvolvimento de uma pesquisa?

- Quais os tipos de pesquisa que vocè conhece e o que engloba cada um deles?

- Qual a importância do uso do método científico para você?

- Por que vocè decidiu fazer a disciplina "INTRODUÇÄO A PESQUISA EM ENFERMAGEM'?

\section{Obtenção dos Dados}

Os dados foram obtidos no primeiro dia de aula da disciplina Introdução a Pesquisa em Enfermagem, quando o roteiro pré-teste com as perguntas foi entregue a cada aluno, e solicitado que estes o preenchessem individualmente. $O$ periodo de coleta de dados foi de agosto de 1990 a março de 1991 . O tempo de preenchimento do Roteiro foi em média de 20 minutos.

\section{- Análise dos Dados}

Para melhor categorizar os dados, inicialmente separou-se as respostas por questäo, reagrupados em 6 grupos. Após, selecionou-se aquelas mais significativas para a nálise e discussão dos resultados, formando-se com isso novos reagrupamentos.

As categorias podem ser definidas por KIENTZ (1973) como a organização de unidades isoladas no "corpus" em grupos, mais ou menos reduzidos, a fim de chegar a controlar a massa e a diversidade.

\section{RESULTADOS E DISCUSSĀO}

Os resultados serāo apresentados e discutidos concomitantemente, a fim de facilitar o entendimento. 


\section{O QUE É PESQUISA CIENTÍFICA PARA VOCÊ?}

Este questionamento teve como finalidade avaliar a percepção do aluno de graduação referente a pesquisa científica como idéia, conceito e/ou valor.

Neste estudo evidenciou-se que a percepção do aluno varia de acordo com o conceito de pesquisa.

Para alguns, é a busca de respostas para as questōes que se propōem a investigar.

"É um método de estudo no qual se obtém respostas ou constataçōes para as dúvidas que surgem na prática."

"E procura de respostas para comprovar um determinado dado que foi observado e que não foi ainda explorado nem comprovado cientificamente."

Para outros a pesquisa científica existem em função do uso do método científico.

"Pesquisa em que se utiliza o método científico com a finalidade de esclarecer determinado assunto."

"É a investigaçáo de um problema observado, utilizando-se uma metodologia científica."

“... E a pesquisa que visa o aprofundamento em um certo assunto buscando-se num método científico."

É importante observar que a percepção dos alunos se complementam umas às outras, demonstrando uma idéia formada a partir de um conhecimento já adquirido.

Verifica-se também que alguns alunos também visualizam a pesquisa científica de forma mais ampla, e global, isto é, extrapolam os limites do método para o processo de coletivação da ciência como objeto de crescimento e desenvolvimento universal.

"É toda pesquisa que possui fundamentação científica, e é voltada para descoberta ou mesmo estudo em prol da ciència e da humanidade."

"É um caminho de desenvolvimento da enfermagem e de todas outras disciplinas, pois ela auxilia no crescimento profissional e individual de cada um."

"A pesquisa científica é de grande valia para todos, afinal a mesma, como diz o título (pesquisa), tem por finalidade descobrir novos conhecimentos e até ressaltar, enfatizar certos conceitos..."

Conceituar pesquisa é uma tarefa árdua o que muitas vezes faz com que as pessoas empreguem o termo indevidamente, devido ao desconhecimento.

Nas respostas ao Roteiro - Pré-teste ficou claro que os alunos procuram definir pesquisa científica da forma como a perceberam em sua vivència de graduação, demonstrando que embora nāo saibam 
conceituar pesquisa com abrangência teórica, o fizeram incorporando conceitos imprescindíveis à sua existência.

Resoluçāo de Problemas, busca de respostas, uso do método científico, inquietaçāo e busca de crescimento profissional e pessoal, foram palavras que se fizeram presentes em quase todos os discursos, indicando que este conteúdo foi transmitido e absorvido pelos alunos de graduaçāo.

De acordo com SILVA (1988) a pesquisa constitui uma das maneiras pela qual uma profissão não só se expressa, como também se estabelece no mundo e que a base para isso se dá através da realização da pesquisa.

SALOMON (1979) e RICHARDSON (1989) indicam que pesquisa científica é um trabalho compreendido metodologicamente, quando surge um problema, para o qual se procura a solução adequada.

Assim, verifica-se que o grupo amostral aprendeu os significados implícitos e explícitos da pesquisa científica.

\section{QUANDO YOCÊ OUVIU FALAR PELA PRIMEIRA VEZ EM PESQUI- SA CIENTÍFICA?}

$O$ referido questionamento tem o objetivo de identificar em que momento do curso de graduação o aluno obteve alguma abordagem sobre pesquisa. Nos depoimentos dos alunos encontramos:

"Quando tinha 8 anos".

Nota-se que o meio de conhecer algo acerca de pesquisa se deu na infância. Entende-se que essa noção adquirida enqua nto ser infante não é suficiente. As exceções relacionam-se as histórias de vida dos cientistas (CASTRO et al, 1985). Segundo PAIM (1979) não temos tradição de pesquisa no que se refere a transmissão da herança cultural em que no contexto familiar, as crianças são incentivadas a desenvolverem trabalhos escolares utilizando-se do método científico. No que se refere a Enfermagem brasileira jamais poderíamos vencer o tempo para forçar a transmissão de conhecimento quanto ao método científico, se contarmos apenas com pouco mais de meio século de existência.

"Quando entrei na faculdade, nos $1^{9}$ e $3^{\circ}$ períodos."

"De forma mais séria, aqui na faculdade."

O citado depoimento encontra respaldo no trabalho de RODRIGUEZ (1979) que enfatiza como uma das funçōes da Universidade o incentivo da iniciação à pesquisa de forma ampla. para que esses conhecimentos não fossem reservados a grupos universitários que detém o poder do conhecimento científico sem adotarem uma política de vulgarizaçāo dos métodos científicos. 
Sabe-se que a iniciação dos conhecimentos de pesquisa deveriam ser oferecidos nos primeiros períodos dos cursos de graduação, entretanto, isto ocorre apenas em alguns cursos como aponta (CASTRO et al, 1985). $\mathrm{Na}$ escola em questão o ensino de pesquisa está integrado ao currículo desde o $1^{\circ}$ período, quando executam pequenas pesquisas de coletas de dados, as quais vão adquirindo uma complexidade progressiva e a partir do $6^{2}$ período é ministrado conteúdo teórico sobre Metodologia da Pesquisa e os alunos elaboram projetos e ou relatórios de pesquisa. Isto ficou evidenciado nos depoimentos a seguir, onde recaiu o maior número.

"No $6^{9}$ período na elaboraçāo de um relatório de pesquisa".

"No $6^{0}$ período na elaboração de um projeto de pesquisa".

"No $6^{2}$ período com grupos menores e deu para se empenhar mais".

\section{QUAIS OS PASSOS PRIMORDIAIS PARA O DESENVOLVIMENTO DE UMA PESQUISA?}

Os alunos participantes do estudo demonstram que reconhecem os passos normalmente utilizados no desenvolvimento de uma pesquisa, devido ao fato de já terem recebido este conteúdo em periodos anteriores, năo como disciplina, mas como unidade integrante de um programa. A disciplina Introdução a Pesquisa em Enfermagem é oferecida aos alunos a partir do $6^{9}$ período do curso de graduação, o que coincide com a elaboração de projeto e/ou relatório de pesquisa.

Isto justifica as respostas dos alunos relativos aos passos primordiais para o desenvolvimento de uma pesquisa, estarem condizentes com o conteúdo teórico ministrado e com o exercício destes passos através da elaboraçāo dos projetos e/ou relatórios de pesquisa.

"Tema, problema, objetivos, hipóteses ou questionamentos. Revisão de literatura, Metodologia. Análise dos dados, Conclusão e Sugestōes". Esta resposta foi dada por 14 alunos do grupo amostral.

Verificou-se também que alguns alunos sentem alguma dificuldade em enumerar os passos de acordo com uma ordem e esquecem alguns elementos, porém isto não significa desconhecimento e sim. falta de prática na utilização.

"Tema, título, justificativa de escolha, universo, a mostra, problema, hipótese. Revisāo de literatura".

"Assunto, tema, titulo, problema, justificativa, metodologia cientifica (instrumento, discurso dos resultados, etc), revisāo de literatura, bibliografia". Neste aspecto 14 alunos colocaram idéias semelhantes. 
Um pequeno grupo (06) não conseguiram estabelecer os passos utilizados para o desenvolvimento de uma pesquisa, colocando ao invés disso conceitos ou idéias.

"Você tem um problema. Deve eleger os objetivos que você deve alcançar. Ter conhecimento científico... "amarrar" o título para que este nāo fique muito abrangente..."

"Deve existir um problema. É importante equacionar a soluçāo e traçar um plano de ação, colocar em prática o que se quer, averiguar o que deu certo e o que se fez. Se alcançou os objetivos".

O uso de passos no desenvolvimento de uma pesquisa científica é incentivado principalmente para facilitar o planejamento e o uso do método científico. Nestes não existe rigidez uma forma única a ser seguida, porém o aluno de graduação necessita de um modelo conceitual inicial para facilitar o desenvolvimento do pensamento científico que é lógico, para no futuro desenvolver a sua própria dinâmica de trabalho.

Hoje em dia com o enfoque qualitativo advindo da pesquisa social, a rigidez quantitativa está sofrendo transformaçōes que só irão enriquecer a busca de conhecimentos e a forma de pesquisar. (GONÇALVES, 1988).

A fim de merecer o qualitativo de científica, a pesquisa deve ser feita de modo sistematizado, utilizando para isto método próprio e técnicas especificas e procurando um conhecimento que se refira a realidade empírica.

Para tanto, o aluno de graduação inicia o aprofundamento científico, aprendendo a desenvolver os passos do método científico, iniciando com o projeto de pesquisa.

O projeto de pesquisa é o produto da reflexāo e conhecimento de um tema de pesquisa. Este é o ponto básico para o desenvolvimento do mesmo.

A partir daí é necessário que se levante a bibliografia existente a respeito do tema para fundamentá-lo nos conhecimentos teóricos existente e comparar a teoria com a prática.

A existência de um projeto de pesquisa implica em planejamento.

$O$ início de uma pesquisa sem planejamento significa alcançar-se à improvisaçāo, tornando o trabalho confuso, dando insegurança ao mesmo, reduplicando esforços inutilmente e que agir desta maneira é motivo de muita pesquisa inacabada, um lastimoso esbanjamento de tempo e recursos.

O projeto de pesquisa ajuda a organizar as idéias de forma que os defeitos e as falhas do raciocínio, assim como as dificuldades de execuçāo possam aparecer antes da pesquisa propriamente dita (TRIVIÑOS 1987; DEMO 1989 e RUDIO 1982. 


\section{QUAIS OS TIPOS DE PESQUISA QUE VOCÊ CONHECE, E O QUE ENGLOBA CADA UM DELES?}

A questão acima tem a finalidade de identificar o conhecimento do aluno relacionado aos tipos de pesquisa e as etapas de cada um dos tipos.

Nos depoimentos concernentes a esta questāo, nota-se uma predominância do tipo de pesquisa quantitativa, seguindo da qualitativa, quanti-qualitativa, campo, bibliográfica, exploratória e descritiva.

$\mathrm{Na}$ trajetória da enfermagem até atingir a etapa dos cursos de Pós-graduação verifica-se que houve uma influência marcante do positivis mo como fundamentaçāo teórica e metodológica para o desenvolvimento dos trabalhos de pesquisa na área (CASTRO et al, 1985). Daí nos depoimentos dos respondentes identificarmos uma predominância sobre o conhecimento do tipo de pesquisa quantitativa, entäo vejamos:

"Pesquisa quantitativa quanto maior do número dos entrevistados, mais fidedigno será o resultado";

"A quantitativa visa as respostas para cada item questionado no instrumento";

"A quantitativa que você trabalha com resultado obtido em cima dos números alcançados (quantidade)", ainda "Pesquisa Quantitativa - levantamento de um problema baseado em dados numéricos e estatísticos na tentativa de influência na solução ou nāo, deste problema através da confirmação das hipóteses elaboradas".

$\mathrm{Na}$ disciplina Introdução e Pesquisa do curso de enfermagem da escola citada anteriormente, enfatiza por demais o tipo de pesquisa quantitativa por entender que seja um modelo que desperta nos estudantes a curiosidade, espírito de observação e de crítica; o hábito de pensar e de resolver problemas por si mesmo e que servirāo de alicerces para as atividades de pesquisa no contexto dos cursos de pós-graduação (ALCÂNTARA, 1964). Ainda, validar hipóteses ou estabelecer novas generalizaçōes sob o método da observação controlada (BOEMER, et al, 1988).

Já, outros depoimentos abordam quanto ao tipo de pesquisa de campo, bibliográfica, exploratória e descritiva, com predominância no tipo de pesquisa qualitativa.

"Conheço a pesquisa de campo e bibliográfica";

"Pesquisa exploratória para conhecer as características ou perfil dos entrevistados";

"Quantitativa, Qualitativa, pesquisa de campo e descritiva".

"Pesquisa Qualitativa - realizada através de uma participaçảo mais efetiva do "pesquisador" e "pesquisado".

"A pesquisa qualitativa vocè trabalha com o resultado obtido aprofundando mais na discussāo teórica destes (qualidade)". 
Dentro desta perspectiva, dos respondentes apontarem diversos tipos de pesquisa, o professor de pesquisa necessita de um sólido conhecimento aliado a uma formaçāo humanista e uma penetração de sentimentos, para que possa conduzir os alunos a uma crescente visão social no sentido de que esses percebem que as pesquisas devem estar aderentes à realidade social (FUNÇÄO, 1949 e CASTRO et al, 1985).

Em se tratando da pesquisa qualitativa que no depoimento dos alunos aparece com predominância, verifica-se que este tipo de pesquisa é recente para o estudo de muitos fenômenos de enfermagem. Observa-se que é um tipo de pesquisa com características próprias; que tem o ambiente natural como sua fonte direta de dados e o pesquisador como principal instrumento, ainda, a preocupaçäo com o "processo" é muito maior do que com o "produto" e que se apresenta sob várias abordagens, com fundamentaçảo filosófica, sociológica ou a ntropológica, que deram origens a diferentes métodos (KAMIYAMA, 1988).

Em suma, ROCHA (1988) ressalta que a enfermagem é constituida de fatos e fenomenos que se realizam todos os dias, mas pelas suas características e complexidade a enfermagem requer várias abordagens. A classificaçāo e a mensuraçāo, caracteristicas da pesquisa "quantitativa", são necessárias, bem como a análise lógica sincrónica e diacrônica, da pesquisa qualitativa.

\section{QUAL A IMPORTÂNCIA DO USO DO MÉTODO CIENTÍFICO PARA VOCÊ?}

Observando os depoimentos referentes ao questionamento acima, nota-se uma abordagem sobre método científico como sendo um conjunto de atividades sistematizadas que fundamenta a teoria da investigação, contribuindo assim, para iniciar um processo de reflexāo e análise do seu trabalho enquanto profissionais da saúde, que culmina com a necessidade de manter-se atualizado de forma mais científica (BOEMER et al, 1990).

"Reconheço que a metodologia tem por finalidade a melhor execução do trabalho e que devo ter maiores conhecimentos sobre ela e seguir a orientação que melhor me adapte".

Outros depoimentos que corroboram com o uso de método científico no sentido de incentivar o desenvolvimento da pesquisa em enfermagem, são:

"É importante para uma organizaçāo da pesquisa, padronizaçāo e para torná-la um trabalho científico".

"Facilita a elaboração da pesquisa, pois é uma forma lógica, ou seja, há uma seqüència de idéias que conduz a conclusảo do trabalho iniciado". 
"O método científico favorece o trabalho de uma pesquisa porque este direciona o teu trabalho, favorecendo um pensamento lógico".

"É de suma importância pois é através do método científico que comprovamos cientificamente solução para os problemas ou a descoberta de fatos novos antes não pensados".

"Tenta mostrar a importância de um fato através da ciência, da pesquisa, tendo um embasamento cientifico".

Um outro depoimento que nos chamou atençāo foi:

"No começo nảo consegui entender muito bem sobre a metodologia científica, mesmo porque a cada período a orientação dada era diferente, ou seja, o que aprendia num período, no outro seguinte era dada totalmente diferente. Até agora já tive (4) professores que deram orientaçōes diferentes".

Tal citaçáo encontra respaldo no dizer de CASTRO et al, (1985) quando menciona que as disciplinas de Metodologia da Pesquisa e Estatística que devem ter como objetivo es pecífico a iniciação à prática da pesquisa, pelo menos à pesquisa quantitativa, não parecem preencher sua finalidade - e às vezes até indispóem o futuro profissional com a pesquisa.

Além, do método científico que contribui para implementação, divulgaçáo da pesquisa em enfermagem, na atualidade temos outras características que fa vorecem ao desenvolvimento da pesquisa cientifica na área, que são os centros de pesquisa, linhas de pesquisas, seminários de pesquisa e a busca de encontrar novos métodos, superando assim, uma das barreiras existentes para o desenvolvimento de pesquisas por parte dos acadêmicos, mestrandos, enfermeiros e docentes de enfermagem (RHODUS, 1979, BOEMER et al, 1990, LOPES, 1983).

\section{POR QUE VOCÊ DECIDIU FAZER A DISCIPLINA "INTRODUÇÃO DA PESQUISA EM ENFERMAGEM"'?}

A disciplina Introdução à Pesquisa em Enfermagem é eletiva com 2 créditos, sendo ministrada em 45 horas de conteúdo teórico e teórico-prático, estando distribuídos em 03 horas semanais. São oferecidas 20 vagas por semestre, devendo estar os alunos pelo menos no sexto período do curso de graduação.

As razóes que levam o aluno de graduação a escolhê-la dentre as outras opçōes que o mesmo tem de disciplinas eletivas variam entre o "desejo de aprender" e a necessidade de "complementar os créditos".

"Para aprender como elaborar uma pesquisa e para ampliar o pouco conhecimento que tenho a respeito do assunto".

"Por apresentar dificuldade em desenvolver uma pesquisa. tenho dúvidas em certas etapas na elaboração da mesma". 
"É uma disciplina importante, para quem quer se dedicar a execuçāo de trabalhos científicos. Adquirir maior conhecimento, visando aprimorar alguns conhecimentos básicos".

$O$ desejo de aprender aparece também aliado a outras necessidades decorrentes do próprio currículo, isto é, no último período de graduaçāo os alunos devem elaborar uma Monografia, que servirá como requisito para concjusão do curso. Assim, a exigência curricular alia-se ao oferecimento de uma disciplina específica eletiva.

"Para poder desenvolver melhor os meus trabalhos de pesquisa e entender como devo encaminhar uma pesquisa sem ficar toda enrolada".

"Ainda tenho dúvidas para confecção do relatório da pesquisa, nāo tenho experiência em pesquisa qualitativa".

"Além de me ajudar na Monografia com mais conhecimentos eu gostei muito de fazer pesquisa".

Houve um depoimento referente ao ensino de pesquisa ministrado ao longo do curso de graduação, por professores diferentes e exigências diferentes.

A falta de unificação nos conteúdos ministrados cria uma angústia no aluno, porque a cada semestre este é orientado a desenvolver os projetos e/ou relatórios de pesquisa de acordo com a visão de cada professor.

"No sentido de auxiliar-me na confecçāo da Monografía e pela dificuldade de se chegar a uma conclusāo sobre pesquisa, já que ao longo dos Programas Curriculares Interdepartamentais (PCIs), cada orientadora nos orientava de uma maneira."

Como a disciplina Introduçāo à Pesquisa é eletiva, alguns alunos decidiram fazê-la devido a necessidade de complementar seus créditos, mas também pelos motivos anteriores como "monografia", "desejo de aprender".

"Em primeiro lugar, a fim de esperar aprender mais sobre pesquisa (por julgar meus conhecimentos muito insuficientes) e em segundo lugar para completar meus créditos".

"Por estar devendo uma eletiva; porque foi a disciplina mais interessante entre as eletivas oferecidas".

"Serve como eletiva e porque é importante para ampliar e acrescentar conhecimentos mais específicos sobre a pesquisa."

Percebe-se pelas respostas que o "despertar" para a investigaçāo científica se faz presente no grupo amostral, já que em nenhum dos depoimentos foi constatado a pesquisa como sendo um "problema" mas sim a solução para estes.

A partir do ensino de pesquisa na graduação o aluno é preparado para interpretar criticamente a realidade objetiva articulando a concepção da prática de enfermagem a um corpo científico de conhecimento, o qual vem sendo visualizada nos últimos dez anos nos registros 
dos Seminários Nacionais de Pesquisa em Enfermagem, revelando uma intensa preocupação em aproximar pesquisa e prática no sentido de construir um conjunto de conhecimentos que leve à recomposiçāo do trabalho em enfermagem (CASTELLANOS e SALUM, 1988).

\section{CONSIDERAÇÕES FINAIS}

Após a análise e discussão dos resultados da coleta de dados verifica-se que os alunos do curso de graduação em enfermagem e Obstetrícia trazem para a Disciplina Introdução a Pesquisa em Enfermagem conhecimentos relativos a pesquisa científica, decorrentes do aprendizado em períodos anteriores, já que o grupo amostral pertence ao último ano do curso.

Percebem a pesquisa científica como o uso do método científico na busca de resposta e questōes da prática e como objeto de crescimento e desenvolvimento profissional global.

A percepção da pesquisa científica ocorre em várias fases da vida, porém se intensifica quando o aluno entra na Faculdade e especificamente no sexto periodo de graduação, quando recebe maior carga de conteúdo de pesquisa e inicia a elaboraçāo de projetos e/ou relatórios de pesquisa.

Os alunos conhecem os passos para o desenvolvimento de uma pesquisa, porém tem alguma dificuldade em enumerá-los por ordem de prioridade. Também sabem diferenciar os tipos de pesquisa existentes, mas com maior facilidade sobre o método quantitativo. Isto ocorre porque no curso de graduação é enfatizado este modelo.

A importância do uso do método científico é percebida pelos alunos no sentido de incentivar o desenvolvimento da pesquisa, divulgação dos trabalhos científicos e descoberta de fatos novos.

Acredita-se que estes resultados positivos relativos ao conhecimento e utilização do método científico é decorrente do Currículo Novas Metodologias implantado na escola de Enfermagem em questão, a qual pretendem desde a implantação do curriculo evitar a fragmentação das disciplinas, a permitir a avaliação do estudante frente às situaçōes vivenciadas no campo prático e a assegurar o domínio das competências profissionais esperadas. (CASTRO et al., 1982).

O fato do aluno de graduação ao ingressar na disciplina Introduçāo a Pesquisa em Enfermagem com interesse e desejo de aprender mais, significa que a disciplina não lhe é estranha, mas sim, que deseja agrupar os conhecimentos adquiridos ao longo do curso.

Uma das idéias orientadoras do Curriculo Novas Metodologias é a integração da teoria a prática, onde o conhecimento teórico e o 
conhecimento prático devem envolver uma dialética que permita a consolidação de um a partir do outro. (CARVALHO, 1978).

Finalizando, acredita-se que este estudo possa servir de subsídios aos professores de graduaçāo para reavaliarem os conteúdos de pesquisa, a fim de que o aluno possa se beneficiar e tornar-se um profissional crítico e aberto a investigaçāo científica.

PADILHA, M. I. C. de S.; CARVALHO, M. T. C. de. The Graduation students and the scientific research. Rov. Esc. Ent. USP., v. 27, n. 2, p. 281-95, aug. 1993.

Investigation about the perception and knowledge of the nursing graduation students with respect to scientific research and its use. The method is qualitative analysis of the contents. The environment is a public nursing school in Rio de Janeiro, the sample consists of 36 students and the tool is a list of 6 questions. The students have a relative scientific research knowledge absorbed along the graduation, mainly from $6^{\text {th }}$ period. They think that the scientific method is important to their development. They choose Research Introduction course as a manner of learning, to develop monographs, to increase their professional skill and to get credits.

UNITERMS: Research. Nursing. Graduation students.

\section{REFERÊNCIAS BILIOGRÁFICAS}

ALCÀNTARA, G. Formaçào e aperfeiçoamento da enfermeira em face das exıgèncias modernas. Rev.Bras.Enf., v.17, n.6, p. 408-19, 1964.

AMADOR, M. et al. El trabajo científico de los estudantes: su papel en la formacion de los profissionais de la salud. Ed.Med.Salud.. v.18, n.4. p. 344-58, 1984.

BOEMER, M.R. et al. Proposta alternativa para a produçáo cientifica de enfermerros assistenciais. Rev.Esc.Enf.USP., v.24, n.2, p. 211-23, 1990.

BRASIL. Ministério da Saúde. Fundação de Serviços de Saúde. Enfermagem: legislação e assuntos correlatos. 3.ed. Rio de Janeiro, 1974. 3v.

CARVALHO, $V$ et al. Um projeto de mudança curricular no ensino de enfermagem em nivel de graduaçáo que favorece aos propósitos emergentes da prática profissional. IN: CONGRESSO BRASILEIRO DE ENFERMAGEM, 30, Belém, 1978. Anais. Belém, ABEn, 1978

CASTELANNOS, B.E.P.; SALUM, M.J.L. A relação entre a peequisa e a prática em enfermagem e no setor saúde: reflexóes e experièncias de enfermeiros do campo num trabalho de pesquisa participante. IN: SEMINÁRIO NACIONAL DE PESQUISA EM ENFERMAGEM, 5, Belo Horizonte, 1988. Anais Belo Horızonte, 1988, p.41-52.

CASTRO. I. B. et al. Reflexáo sobre a prática de enfermagem no Brasıl e na América Latına: implicaçóes educacionaıs. Rev.Bras.Enf., v.35, n.2, p. 185-91, 1982. 
CASTRO, I.B. et al. Dificuldades na incorporação dos resultadoo de peoquisa na prática da enfermagem. IN: SEMINÁRIO NACIONAL DE PESQUISA EM ENFERMAGEM, 4, Sáo Paulo, 1985. Anais, Sāo Paulo, ABEn/Finep, 1985. p.193-242

DEMO, P. Metodolode cientrfica em cióncias socinis. 2.ed. Såo Paulo, Atlas, 1989.

A FUNÇẢO docente e sua eficiência./Editorial/ RBRP, v.13, n.37, p.3.4, 1949.

GONÇALVES, R.B.M. Trabalho em saúde e pesquisa: reflexāo a propósito das possibilidades e limiteo da prática de enfermagem. IN SEMINARIO NACIONAL DE PESQUISA EM ENFERMAGEM, 5, Belo Horizonte, 1988. Anais. Belo Horizonte, 1988, p. 27.39.

KAMTYAMA, Y. Apresentaçāo IN: ENCONTRO INTERAMERICANO DE PESQUISA QUA. LTTATVA EM ENFERMAGEM, 1, São Paulo, 1988. Anais. EEUSP/DEUFSC, 1988.

KIENTZ, A. A comunicaçăo de magara análise de conteuido. Rio de Janeiro, Eldorado, 1973.

LOPES, C.M. A produçào dos enfermeiros asuistencinie em relaçào d̀ pesquisa em enfermagem, em um município paulista. Ribeirào Preto, 1983. 133p. Dissertaçáo (Meotrado).Escola de Enfermagem de Ribeiráo Preto, Univeroidade de Sáo Paulo.

PAIM, L Questóes e mitos acerca de modelos de asoistóncia de enferma gem. IN: CONGRESSO BRASILEIRO DE ENFERMAGEM, 31, Fortaleza, 1979. Anais. Fortaleza, 1979.

PORTO, I.S. O processo ensino/aprendizagem de pesquisa no Curso de Graduação om Enfermagems perspectiva do profeosor. Rio de Janeiro, 1990, 179p. Tese (Mestrado)-Escola de Enfermagem Anna Nery, UFRJ.

RICHARDSON, R. Pesquisa social: métodos e técnicas. São Paulo, Atlas, 1989.

RHODUS, C.C. Preparo e aperfeiçoamento de recursos humanos para a enfermagem. IN: CONGRESSO BRASILEIRO DE ENFERMAGEM, 31, Fortaleza. 1979. Anais . For. taleza, 1979.

RINEHART, J.M. One way to learn research proces. Nurs.Outlook, v.24, n.1, p.38-40, 1976.

ROCHA, S.M.M. Pesquisa e enfermagem. Rev.Bras.Enf., v.41, n.2, p. 91. 1988.

RODRIGUEZ, M.I. El trabajo cientifico en la formacion de profissionales de la salud. Ed.Med.Salud., v.13, n.3. p. 212-28, 1979.

RUDIO, F.V. Introdução ao projeto de pesquisa científica. Petrópolis, Vozes, 1982.

SALMON, D.V. Como fazer uma monografia. 6.ed. Belo Horizonte, Interlivros, 1979.

SILVA. E.M.P. História da ciència. IN: SEMINÁRIO NACIONAL DE PESQUISA EM ENFERMAGEM, 5, Belo Horizonte, 1988. Anais. Belo Horizonte, 1988. p.21.6.

TRIVIÑOS, A.N.S. Introduçào a pesquisa em cièncias sociais: a pesquısa qualitatıva em educaçáo. Sào Paulo, Atlas, 1987. 